\title{
Management of Coastal Aquifers with special reference to seawater intrusion and its remediation.
}

\author{
Muhammad Zaid Qamar ${ }^{\mathrm{a} *}$, Tabinda Araib ${ }^{\mathrm{b}}$, Sumbul Parveen ${ }^{\mathrm{b}}$, Wahid Ali ${ }^{\mathrm{c}}$ \\ a zaid.qamar40@gmail.com \\ ${ }^{a}$ Department of Geology, Aligarh Muslim University, Aligarh 202002, India \\ ${ }^{b}$ Department of Geology, Aligarh Muslim University, Aligarh 202002, India \\ 'Department of Chemical Engineering Technology, Jazan University, Jazan 45142, Kingdom of Saudi Arabia
}

\begin{abstract}
Coastal areas are home to a significant portion of the world's population, which is mostly concentrated in major cities. In India alone 28.62 million which is almost 25 percent of people living in the state live near the coastal areas. Population and economic development continue to bring pressure on already-strained water supplies, putting coastal aquifers at risk of seawater intrusion. Groundwater salinization has occurred in coastal areas all over the world as a result of intensive groundwater abstraction. Rising sea levels and storm surges as a result of climate change, as well as land subsidence, are expected to escalate the problem in the coming decades. The handling of coastal aquifers includes identifying an appropriate body of salt water and calculating the amount of freshwater discharging in the sea which is needed to maintain the seawater-freshwater interface. Although data are the most important precondition for management, good governance is also essential. Groundwater supplies face some general governance problems due to invisibility of ground water management is a pressing problem due to the increased dependency on it. The paper discusses common governance problems and the remedial measures that can be taken against seawater intrusion in coastal aquifers with great detail along with 4 case studies discussing water management challenges in coastal zones and improved methods of aquifer recharge. Remedial measures using conventional and temporary methods as well as modern methods like hydraulic barriers are also discussed and elaborated.

Published by IJRP.ORG. Selection and/or peer-review under responsibility of International Journal of Research Publications (IJRP.ORG)
\end{abstract}

Keywords: seawater intrusion; coastal aquifers; climate change; governance.

\section{Introduction}

Groundwater is considered one of the most important sources of water in many coastal areas. As the water demand increases, the abstraction of water from aquifers also increases which leads to lowering of the water table, hence, causing salt water intrusion. Saltwater intrusion is one of the root-checks which degrades the quality of groundwater and causes a major challenge in management of groundwater resources in coastal regions.

Meanwhile, management must be implemented to overcome this situation within the framework of management of the coastal zone. Groundwater supplies face some general governance problems due to invisibility of ground water management is a pressing problem due to the increased dependency on it. Over extraction and contamination often result in increased groundwater pressure and has placed coastal 
groundwater supplies in jeopardy. Climate change is also affecting the groundwater supplies, the pressure on groundwater supplies will increase if recharge declines or droughts last longer.

In this world, almost 37 percent of the people live near the coastal areas which is almost twice more than the population density of the world. And talking about India, the population of the coastal districts is 28.62 million which is almost 25 percent of people living in the state. If current levels of population growth and industrial developments are not regulated soon, managing seawater pollution will become a major challenge.

\section{Variability of Coastal zones}

Human settlement and economic activity have always gravitated to coastal zones. Within 100 kilometres of the coast, $37 \%$ of the world's population lives, and the population density in these areas is twice that of the rest of the world. Shorelines are home to two-thirds of the world's cities. Coastal zones around the world are experiencing unprecedented population growth, especially in urban areas. China is the epicentre of this development, with a projected population of about 200 million people in low-elevation coastal zones by 2030 , but India, Bangladesh, Indonesia, and Vietnam's coastal areas are also experiencing rapid population growth. A rise in water demand is being caused by an increasing coastal zone population, shifting lifestyles (higher water use per capita), agricultural expansion, and economic growth. The high local demand is due to urbanisation. Rainfall and surface waters are visible aspects of the hydrological cycle, but the main freshwater supplies are deep, in the form of groundwater in aquifers, in terms of volume.

Coastal aquifers are subjected to a variety of processes. Some, like climate change or tectonic uplift, have only a long-term effect, but devastating events like tsunamis or storm surges can have major effects in a matter of seconds. Low-lying areas, such as river deltas or atoll islands, are particularly vulnerable to land subsidence. A higher occurrence of severe weather events in these areas will lead to more frequent storm surges and seawater flooding of the land surface. Freshwater supply protection in coastal areas is thus intertwined with shoreline protection, as well as land use and urban planning.

Coastal water management is a highly specialized process and one of its main aims is to protect production wells from salinization. It must balance the growing demand for water with the capacity of the aquifer to deliver water of good quality, making sure at the same time that other functions of groundwater, like that of a water source to ecosystems, are not compromised. The concept of "the coastal groundwater squeeze" was coined by Michael et al. (2017) to describe the ever-growing pressure on freshwater resources in coastal aquifers. The multitude of threats and the connectedness of aquifers with various parts of the natural and anthropogenic hydrological cycle highlight the need for integrated water resources management (IWRM, Cap-Net 2010), as groundwater cannot be managed separately from other water sources.

Since groundwater cannot be handled separately from other water supplies, the multitude of threats and the interconnectedness of aquifers with different sections of the natural and anthropogenic hydrological cycle illustrate the need for integrated water resources management (IWRM, Cap-Net 2010).

\section{Effects of Climate Change and sea level rise}

The susceptibility of a coastal aquifer system to salinization is characterised by the degree to which it is "vulnerable to and unable to cope with the adverse effects of sea level rise or groundwater depletion," according to the Intergovernmental Panel on Climate Change. The fact that changes in temperature and precipitation will cause a difference in recharge is not expressly considered in this description. The pressure on groundwater supplies will increase if recharge declines or droughts lasts longer, particularly if higher temperatures lead to higher evapotranspiration rates and, as a result, increased water demand for irrigation and domestic water use. Over the twenty-first century, sea levels are predicted to rise by several decimeters along most of the world's coastlines. The extent of the effect on fresh groundwater supply is difficult to estimate a 
priori and is highly dependent on local hydrological conditions. Due to a landward movement of the seawater wedge, sea level rise is expected to result in a lack of fresh groundwater and a higher rate of floods in the majority of situations. However, in some cases, rising sea levels may result in increased freshwater supply. This may sound counterintuitive, but a higher sea level will raise freshwater storage by increasing the water table without altering the location of the fresh-saltwater interface. If sea level rise is not caused by land degradation due to increased coastal erosion or flooding in low-lying areas, this is the case for some atoll islands (White and Falkland 2010).

Although future climate change is a true and pressing issue, the salinity distribution in many coastal aquifers is partially a result of historical hydrological conditions. Throughout geological history, sea temperatures, coastal positions, and recharge times have all been complex. Relic seawater still remains in the aquifer environment in marine regions where the shoreline has been farther south, as it had been in several maritime zones over the centuries. During the Quaternary glacial ages, on the other side, large swaths of seafloor dried up, creating freshwater reservoirs. Several sites around the globe have retained these under the seafloor. Such dynamics show how forecasts based on overly simplistic interpretations of natural systems and human drivers in coastal zones can be inaccurate.

\section{Impacts of natural disaster on coastal aquifers}

Storm surges and tsunamis are common in low-lying coastal areas. They are a danger to fresh freshwater supplies, in addition to their direct devastating effects on human lives and facilities. Seawater infiltrates the surface after an inundation, contaminating the new groundwater. Since seawater pools in topographic depressions and large-diameter drilled wells do not drain out to the sea after a flood, they are highly fragile. The effect on unconfined aquifers is the largest. Deeper, confined aquifers are better insulated against shortterm danger, but they can have harmful long-term effects.

Following the Tsunami of 2004, groundwater salinization was recorded in India, Sri Lanka, and Indonesia. Thousands of shallow water wells in the coastal area of the Province of Nanggroe Aceh Darussalam in northern Sumatra were contaminated by the tsunami in Indonesia. Owing to a lack of information about local hydrogeological conditions, several recent drillings failed to locate potable water after the earthquake destroyed the reticulated water supply grid. As a result, the water quality was severely harmed. Nine months after the disaster, geophysical airborne investigations revealed salt water several kilometres inland. Salinization of deeper groundwater occurs as a result of storm surges, such as those experienced on Samar Island, Philippines, during Typhoon Haiyan in 2013. Seawater infiltrating from the ground floor contaminated the upper aquifer, which reached a height of 7 metres above mean sea level. Poorly-sealed tube wells primarily polluted the deeper enclosed aquifer. The salinity decreased dramatically after 8 months, but the possibility of pollution of deeper freshwater persists because salinities in the shallow unconfined aquifer are expected to remain elevated for many years.

Shallow soil salinization also occured in 2013 in Samar Island, the Philippines, following storm uprisings such as those occurring in typhoon Haiyan. Seawater infiltrating from the ground floor contaminated the upper aquifer, which reached a height of 7 metres above mean sea level. Poorly-sealed tube wells primarily polluted the deeper enclosed aquifer. The salinity decreased dramatically after 8 months, but the possibility of pollution of deeper freshwater persists because salinities in the shallow unconfined aquifer are expected to remain elevated for many years.

Another cause for seawater intrusion may be a lowered land area relative to sea level. The coastal areas with dense subsurface layers of clay and peat are vulnerable to subsidy. In the delta regions threatened by land loss, approximately a half billion people live. The key cause is the loss of the structure of rock grains on the subsoil, mainly as a result of excessive pumping of groundwater (USGS 2016). The decrease of the water table by land drainage, which can lead to massively oxidising organic soils of carbon in peat zones, is another cause of land decrease. 
Quickly rising urban areas need large quantities of water, often resulting in overfishing of groundwater resources for domestic and industrial water supplies. The continuous large-scale mining in the city of Dhaka in Bangladesh, for example, currently reduces the levels of groundwater by 2-3 metre annually. Foundation water extraction is causing significant land decline and other coastal towns, such as Jakarta (Indonesia), Ho Chi Minh City (Vietnam), and Bangkok, experience similar conditions (Thailand). The global average present increase in sea level is around $3 \mathrm{~mm} /$ year. It is anticipated that this rate will rise in future (IPCC 2013), but in some coastal Megacities, it remains fairly low compared with subsidies of 6-100 mm/year. This again shows that the main risk factor for marine intrusion are human activities.

\section{Groundwater Problems in governance.}

Groundwater supplies, whether along the coast or inland, face some general governance problems due to the 'invisibility' of groundwater. Groundwater management is a pressing problem due to the increased dependency of economies and livelihoods on groundwater almost everywhere on the planet as rainfall and runoff trends become less reliable. Over-extraction and contamination often result in increased groundwater pressure.

Joint resource management necessitates not only administrative changes, but also changes in people's views of the resource. Groundwater processes, on the other hand, are more difficult to detect and measure than surface water processes. The dynamic hydrogeological processes at the saltwater/freshwater interface in coastal areas are therefore difficult to imagine for non-experts.

\section{Water management challenges in coastal zones}

\section{Rapid population growth}

\section{Case Study of Dar es Salaam, Tanzania}

\section{Introduction:}

Dar es Salaam is one of the fastest growing city centres in Africa. In 1957, Dar es Salaam had a population of 128,000 , but today it amounts to approximately 4.1 million. It is likely to become "megacity" by the beginning of 2030 - over 10 million residents (African Development Bank 2014). In 2016, 51\% of Dar es Salaam's population was supplied with piped water according to Skinner and Walnycki. The nearby Ruvu River and Kimbiji Aquifer, a 600-meter deeper aquifer, are often taken from this water. Other residents most of whom live in informal and low-income neighbourhoods not linked to public networks - get their water from the shallow waterfall under the town. Intrusion of seawater has occurred in the town centre near the shore, which has concentrations of chloride above the WHO suggested $250 \mathrm{mg} / \mathrm{l}$ drinking water level.

\section{Consequences}

Seawater intrusion is caused by accelerated urbanisation in two ways. The major land use changes in the region, on the one hand, because of the spread of new settlements in the coastal plain and the urban infrastructure, minimise intrusion by precipitation. On the other hand, abstraction from the superficial aquifer is rising rapidly in order to satisfy increased demand. The shallow aquifer is currently tackled by up to 10,000 unregulated boreholes. A single unified institutional umbrella is required for long-term management that prevents more seawater intrusion. Data-driven management is required, which necessitates systematic monitoring of the shallow aquifer as well as water supply and usage variability.

\section{The Consequences of Sand mining:}




\section{Case Study of Nilwala river basin, Sri Lanka}

\section{Introduction}

The salinity of water in coastal zone rivers is regulated by several factors, including river discharge and morphology. Natural cycles such as flooding, as well as sedimentation and erosion, and human actions such as dam building and dredging, have an effect on both. Riverbed sand mining has increased dramatically in southern Sri Lanka over the last 25 years. Economic development and the reconstruction of tsunami damage from 2004 are the main drivers of high sand demand. The Nilwala River is a watershed that has been severely impacted by sand mining. The riverbed has been lowered as a result of increased sand production since 1997. The riverbed of the Nilwala has been 4.5 metres below sea level in the estuarine reach near Matara since 2008, and it will not reach sea level until 28 kilometres upstream near Akuressa. As a result, during the dry season, when river discharge is minimal, seawater will pass upstream.

\section{Consequences}

Matara's drinking water is sourced from aquifers under the coastal plain. Water supply wells near the Nilwala River have shown rising salt concentrations over the last 20 years, necessitating their relocation upstream. The key development used to be 8 kilometres from the beach, but it is now more than 18 kilometres inland in Kadduwa. Increased salinity of river water has an effect on agriculture and habitats in the area. The Sri Lankan Water Alliance, in collaboration with partners from academia, civil society, and international organisations, is working to minimise sand mining. Given that sand mining legislation exists but that compliance is poor, the emphasis is on raising awareness among law enforcement agencies such as the police and environmental and mining regulatory authorities.

\section{Importance of Coastal Groundwater resources in India}

Proper and effective management of coastal groundwater supplies is critical and is an important component of coastal zone management. Overexploitation has placed coastal groundwater supplies in jeopardy. Overpumping allows seawater to flood freshwater aquifers when groundwater-bearing formations are hydraulically attached to the sea. Thus, seawater intrusion is the flow of seawater into the aquifer from the land, which is normally triggered by excessive groundwater extraction. Rainfall recharge is limited as land use shifts as a result of urbanisation.

Groundwater is used in more than $60 \%$ of irrigated crops and in $85 \%$ of drinking water sources(World Bank 2012). Owing to inadequate and insufficient municipal water sources, urban residents are increasingly dependent on groundwater. Almost 7516 kilometres of the country is maritime, while $25 \%$ of the country's inhabitants live on the coast. The simple availability of water is responsible for the high population density along the coast. The coast is home to the population of three metropolitan cities out of four, including Chennai, Mumbai, and Kolkata, as well as several urban centres including Puri, Visakhapatnam, Nellore, Puducherry, Cuddalore, Nagapattinam, Tuticorin, Trivandrum, Cochin, Mangaluru, Goa, Surat, and Diu. Due to this reason the coastal region is the most industrialized region of India.

\section{Salinity}

The salinity in freshwater and seawater varies greatly chemically, as determined by the gross dissolved solids (TDS) concentration. $1000 \mathrm{mg}$ TDS/L is commonly used as the upper limit for TDS in freshwater. The average TDS/L of ocean water is $36,000 \mathrm{mg} / \mathrm{L}$, although there are differences across this figure. For example, salinity may be significantly lower at the mouths of major rivers or significantly higher in warm climates with 
heavy evaporation. The dissolved chloride ion is the most important part of TDS in seawater. Although there is no health cap for chloride in drinking water (World Health Organization, 2003), chloride concentrations greater than $250 \mathrm{mg} / \mathrm{L}$ are detectable by taste. This suggests that a combination of freshwater and $1 \%$ seawater will already be unfit for human consumption.

Seawater has a greater density than freshwater due to its high salinity. For ocean water, the difference is around 2.5 percent. Although this disparity may seem insignificant, it has significant consequences for the physical mechanisms that control the movement of seawater into freshwater aquifers. The density of seawater ranges considerably between locations, with the lowest density occurring in inland waters with freshwater inflow, such as the Baltic Sea, and the highest density found in regions where evaporation is the predominant cause of water depletion, such as the Dead Sea. As a result, it must be decided as part of every coastal aquifer study.

\section{Fresh water and sea water interaction}

Hydraulic conductivity is a measure of a geological unit's ability to conduct water. The simpler it is for a device to transmit water, the better its hydraulic conductivity. Based on this parameter, layers in the subsurface are classified into so-called hydro-stratigraphic units, with the more permeable layers forming aquifers and the less permeable layers forming aquitards. Aquitards are made up of clay, gravel, or mudstone, while good aquifers are made up of coarse sand, granite, or broken rocks. A transition zone separates fresh groundwater and intruded seawater where they intersect in a tidal aquifer.

The greater density of seawater relative to freshwater causes this configuration: A seawater column exerts more weight than a freshwater column of equal volume. As a result, seawater will seep into the aquifer under the ground surface inland from the coast. The length of time the seawater wedge can protrude inland is determined by many factors:

The greater density of seawater relative to freshwater causes this configuration: A seawater column exerts more weight than a freshwater column of equal volume. As a result, seawater will seep into the aquifer under the ground surface inland from the coast. The length of time the seawater wedge can protrude inland is determined by many factors:

- Processes of groundwater recharge and discharge

- The aquifer system's hydraulic properties and geometry.

- The disparity in density of fresh groundwater and seawater.

In addition, the lower the seawater wedge's penetration into the aquifer, the greater the seaward flow rate of fresh groundwater. A higher hydraulic conductivity of the aquifer, on the other hand, would result in a greater inland extent of the saltwater wedge with the same flow rate. The effect will be the same if the density difference is greater.

\section{Types and causes of seawater intrusion}

Coastal aquifers are located in some of the world's most highly mined regions. "The amount of groundwater usage will rise significantly, to the point that managing seawater pollution becomes a major challenge for potential water resources management engineers," if current levels of population growth and industrial development are not regulated soon. Saltwater pollution is a big concern in coastal areas around the world. That can happen as a result of human activity as well as natural disasters like climate change and sea level rise."

The key reasons for the intrusion of saltwater are: Overabstraction of the aquifers, Seasonal changes in natural groundwater flow, Tidal effects, Barometric pressure, Seismic waves, Dispersion, Climate change - global warming and associated sea level rise (Abd-Elaty et al 2017). 
There are various types of seawater intrusion which includes: Seawater intrusion into an aquifer next to the sea from the side, Downwards seepage from a saline surface waterway that overlies an aquifer, Upcoming of deep saline sea water contained in an aquifer, Changes to the natural barriers that distinguish seawater from an aquifer, Increasing the amount of groundwater extracted. (Abd-Elaty et al 2017).

Identification of Seawater Intrusion.

\section{Groundwater Head}

The best way to track seawater penetration is to measure the groundwater head in comparison to the sea level. The Ghyben-Herzberg relationship is used to determine where the freshwater-saltwater interface is located. The gui would be present at 40 metres below mean sea level if the groundwater level is one metre above mean sea level. If the groundwater level above mean sea level is 0 , the interface would appear above the mean sea level. Centered on the Ghyben-Herzberg relationship, Inouchi et al. (1985) determined the interface in the estuaries of the Nakka and Kiki Rivers in Japan.

\section{Geophysical Methods}

Seawater penetration is observed using geophysical techniques based on resistivity values. The conductivity of the groundwater is indirectly proportional to the resistivity of the soil. Groundwater typically has a high resistivity rating. Low resistivity values are seen in coastal environments, suggesting the presence of seawater. Geophysical techniques are helpful in calculating the level of seawater penetration when measuring wells are not available.Using the high resistivity electrical resistivity tomography technique, the region of mixing between freshwater and saltwater in Chennai, India was visualised. Melloul and Goldenberg (1997) used the time domain electrical method resistivity values to investigate saltwater infiltration in Israel's coastal aquifers.

\section{Geochemical Investigations}

The evolution of the sources, pathways, rates, and potential salinization of coastal aquifers depends on the differentiation of different salinization mechanisms. The sources of salinity in coastal aquifers can be determined using a number of geochemical parameters.

1. $\mathrm{Cl}$ concentration: In groundwater, a $\mathrm{Cl}$ concentration of $200 \mathrm{mg} / \mathrm{l}$ is used as an indicator of saltwater intrusion.

2. $\mathrm{Cl} / \mathrm{Br}$ ratios: the bromide ion is an excellent source of saltwater intrusion. Bromide concentrations in freshwater are less than $0.01 \mathrm{mg} / \mathrm{l}$.

3. The sodium-to-chloride $(\mathrm{Na} / \mathrm{Cl})$ ratio.

4. Calcium/ $\mathrm{Mg}$ and calcium/(HCO3 $+\mathrm{SO} 4)$ ratios

5. Isotopes of $\mathrm{O}$ and $\mathrm{H}$.

6. Isotopes of boron. 


\section{Isotopic Methods}

The stable isotopes of oxygen (18O) and hydrogen $(2 \mathrm{H})$ have been extensively used to investigate the sources and dynamics of groundwater. The distribution of these isotopes was used to investigate the origins of different water forms and their interactions. Each body of water has its own isotopic signature. The high difference in isotopic signature between freshwater and seawater confirms the process of seawater penetration. The stable isotope contents of light elements are commonly used to express isotopic ratios. Isotope concentrations are expressed as variations between the ratio of the sample and the same ratio in a globally agreed norm due to minor differences in isotopic ratios (e.g., 2H/1H) (IAEA, 1994). VSMOW (Vienna-Standard Mean Oceanic Water) is a standard ocean water.

\section{Tidal activity}

Several investigators have investigated the effects of tidal action on coastal groundwater quality using laboratory experiments, field studies, and modelling studies. During high tide, the seawater interface induces an inflow of seawater into the pumping wells. According to Einsiedl (2012), the natural conduits that provide water to tube wells could also be used to carry tide-induced seawater into inland areas. Furthermore, experiments have discovered that tides influence not just the freshwater-seawater mixing region, but also the rate of groundwater drainage into the sea, allowing the freshwater-seawater interface to thicken. The study also showed that variations in the tides have major impact on the water level in the shallow aquifer, while during the groundwater discharge into the sea, the beach slope plays a major role. (Ataie-Ashtiani et al., 2001; Li et al., 2002).

\section{Human induced factor}

All other factors governing seawater intrusion are directly or indirectly linked to human activities. The most significant human-induced mechanism that raises seawater infiltration in coastal regions is overexploitation of groundwater supplies. In coastal zones, groundwater is mainly used for residential, farming, and industrial uses. Groundwater supplies are over-exploited as a result of increased water demand, resulting in seawater infiltration. In several areas of the world, including Africa, excessive groundwater withdrawal has been identified as the primary source of seawater infiltration (van Camp et al., 2014)

\section{Mitigation Measures}

To protect freshwater reservoirs and to remediate areas threatened by seawater pollution, mitigation steps should be followed. In coastal zone management, seawater intrusion prevention is essential. The numerous approaches for dealing with seawater contamination

\section{Conventional Methods}

\section{Reduction in Pumping}

The purity and usual utility of groundwater are harmed as seawater is mixed with it. As a result, groundwater overpumping of the coastal aquifer can be minimised. This approach is both cheaper and more efficient at preventing seawater intrusion.

Rearranging of Pumping Wells 
The movement of the interface landward would be intensified by excessive groundwater extraction in the seawater-intruded region. The seawater-affected pumping wells can be rerouted to the landward side, away from the interface. This approach is cost-effective, and optimal freshwater pumping can be performed to avoid seawater intrusion. To deter seawater infiltration, groundwater pumping stations near the shore in Chennai were moved away from the sea. Seawater intrusion was minimised in sections of the Nile Delta aquifer by rearranging pumping wells.

\section{Increasing Groundwater Recharge}

Recharging the groundwater increases the amount of available freshwater, allowing the interface to shift closer to the sea. Precipitation is the primary source of water for recharging groundwater. Rainwater may be gathered and deposited in reservoirs or wetlands, and used to rehydrate the groundwater. Recharging the groundwater increases the amount of available freshwater, allowing the interface to shift closer to the sea. Precipitation is the primary source of water for recharging groundwater. Rainwater may be gathered and deposited in reservoirs or wetlands, and used to rehydrate the groundwater.

\section{Injection Wells}

Injection wells are tube wells built for the purpose of freshwater recharge that cause the interface to travel directly into the sea. Freshwater is pumped under high pressure into the injection wells, causing seawater to drain backward. This approach is not widely used since it is based on the supply of freshwater to inject. The interface can be pushed closer to the coast by recharging injection wells and increasing the injection rate.

\section{Saltwater Pumping Wells}

Pumping saltwater from a seawater-intruded coastal aquifer would minimise the amount of saltwater available and improve groundwater quality. This process is costly, and absolutely pumping out the saltwater is challenging. Pumping out saltwater was used to mitigate seawater pollution in Chennai.

\section{Physical Barrier (Subsurface Barrier)}

The subsurface barrier is built under the surface to prevent seawater from moving inland. This barrier would increase the volume of groundwater that can be contained in the aquifer, increasing freshwater supply. The cement grouting process was used to construct the shield, which is supported by an impervious stratum. In a limestone coastal aquifer on Okinawa Island in the western Pacific Ocean, a subsurface shield protects the aquifer from seawater intrusion.

\section{Modern Methods}

\section{Subsurface Engineering approaches:}

Preventing seawater penetration with subsurface engineering is typically costly and involves a complex technological infrastructure. As a result, there has been little adoption, and there are just a few comprehensive accounts in the literature.

\section{Hydraulic Barriers}


Hydraulic barriers have become more common than other management techniques for controlling SWI. Hydraulic barriers are known as recharge, abstraction, or a combination of abstraction and recharge. Treated wastewater (TWW), desalinated seawater, and desalinated brackish water are three potential water sources for aquifer recharge. TWW refers to reclaimed wastewater that has been properly treated in treatment facilities. Both microbial contaminants, suspended solids, oxygen-depleting organic matter, and nutrients (i.e. nitrogen and phosphorus) in treated effluents from sewage treatment plants are substantially reduced using a combination of mechanical and biological methods.

Desalination is the method of extracting dissolved minerals (primarily salts) from seawater or brackish groundwater to create potable water. Desalination can be achieved using a variety of techniques that fall into two categories: thermal (distillation) processes and membrane processes.

The desalination method can be chosen based on three key considerations: technological, environmental, and economic. The aim of the desalination process is to reduce the amount of energy used and, as a result, the overall cost of the water generated. Reverse osmosis (RO) is a membrane-based water desalination technique that is currently one of the fastest-growing. RO uses less electricity, so it's less expensive and emits less greenhouse gases. It also needs relatively simple machinery, doesn't need to be connected to a power plant, and only takes up a small amount of ground. RO is a pressure-driven technique that uses dynamic pressure to resolve the salt solution's osmotic pressure. Water is pushed through small pores at high pressure through semi-permeable membranes, while concentrated brine solution is rejected. The pressure difference must be large enough to resolve water's natural propensity to shift from the low salt concentration side to the high salt concentration side of a membrane, as described by osmotic pressure. The process of generating friction consumes the most electricity. The efficiency of the membranes, the pressure, and the salinity of the produced water all influence the consistency of the water.

\section{Artificial Recharge}

The aquifer is artificially recharged by high-quality water (e.g., surface water, rainwater, pumped groundwater, treated wastewater, or desalinated water) within the positive or pressure barriers to preserve the system's seaward gradient by increasing the inland piezometric heads. In general, artificial water recharge aims to minimise flood flows, store freshwater in aquifers, increase groundwater levels, alleviate overpumping, enhance water quality, and suppress saline water bodies.

\section{Abstraction Barriers}

The brackish or salty water is continuously pumped into deep abstraction wells along the coast in negative barriers. The collected water may either be dumped into the sea or used as a source of water for desalination plants.

\section{Combined barriers}

By combining the merits of the individual methodologies, some of the aforementioned techniques will help to better control SWI. For example, a potential solution for SWI has been documented in the literature as a combination of reduced pumping rates and recharge barrier, as well as regulating the pumping rate with artificial recharge.

\section{Improved Method of aquifer recharge}


Multiple steps to improve groundwater recharge can be taken. Any of them are related to urban and land use planning, such as green space or decentralised water penetration. In addition, land cover improvements can have positive side effects on groundwater refuelling, for example, whether they are socially and ecologically suitable for removing vegetation that is high in water demand. Another strategy that is particularly applicable in temperature conditions that are marked by distinct rainy and dry seasons is underwater storage of excess water. The water surplus can be pumped into a water tank during the rainy season and deposited in it for dry season use.

For an effective implementation, it is critical to have a thorough understanding of the target aquifer's storage and recovery ability, future water quality improvements, and harvesting potential based on precipitation data. Two case studies of artificial recharge are presented in this section. The first (Kerala, India) is low-cost and can be introduced at home using specific technical tools. The second (in the southwest Netherlands) necessitates more advanced technologies and higher investments, with the aim of increasing farm irrigation water supply.

Case1: Rooftop rainwater harvesting for dug wells (Kerala, India)

\section{Introduction}

About $80 \%$ of the households in Kerala, on India's southwestern coast, depend on groundwater. The water comes from shallow wells, which can be found in the state's coastal area at a rate of up to 400 wells per km2. Since the soil has a low infiltration potential, there is limited groundwater regeneration despite the high annual rainfall of about $3,000 \mathrm{~mm}$, which is concentrated in two monsoon seasons. As a result, during the dry summer months, the water table decreases, and $70 \%$ of shallow wells run dry (Planning Commission-GoI 2008). Saltwater intrusion has also occurred along lagoons and tidal rivers, with illicit sand mining from coastal riverbeds exacerbating the problem.

\section{Technology:}

During the monsoon months, there is a lot of rain, which provides a lot of water storage capacity. The Mazhapolima project, which began in 2008, built infrastructure to collect rainwater from rooftops and divert it into open wells, with the aim of storing it in the aquifer. Water is filtered through a sand and charcoal filter or a textile filter made of nylon or fabric before being injected. Water seeps into the nearby aquifer until the well is capped with water. 20,000 harvesting units have been built since the Mazhapolima project started in 2008. The price of each unit varies depending on the type of filter, ranging from $\$ 75$ to $\$ 100$ (textile filter) and (sand and charcoal filter) respectively. Since the salinity of infiltrated water in coastal areas is lower than that of ambient groundwater, groundwater quality near wells increases (NITI and UNDP 2015). Although dug wells assist in the penetration of rainwater into the aquifer, they also have the potential to become a source of aquifer pollution. There have been rumours of wells being used as sewage dumps, resulting in bacterial contamination of the recharged water (NITI and UNDP 2015). For the success and sustainability of this method, sound capacity building and monitoring of the water along the process (ambient groundwater, source water for infiltration, recovered water) as well as technical infrastructure (filters, wells) in the households are essential. This involves maintaining an up-to-date, geo-referenced list of wells and infiltration facilities, as well as having knowledge tools to deal with dug wells, even though they are no longer used as infiltration wells. This approach's promotion should be coordinated with competent water authorities, or followed by initiatives to improve groundwater-user groups capable of aquifer security.

Case 2: Innovative freshwater lens management

(Zeeland, the Netherlands) 


\section{Introduction}

A significant portion of the Netherlands is submerged in the sea. As a result, salinization affects groundwater supplies in the country's coastal areas, posing a major challenge for agricultural and drinking water supply management. Freshwater will be placed under more stress as a result of climate change, sea level rise, and land subsidence, especially during the summer. Groundwater that is brackish and salty is often encountered at shallow depths. Freshwater lenses created by infiltrated rainfall in brackish or saline aquifers are the only source of water for agricultural activities in these areas. The thickness of the lenses varies from $>50 \mathrm{~m}$ in dune areas to 5 to $20 \mathrm{~m}$ in fossil sandy creeks and 1 to $2 \mathrm{~m}$ in polder areas.

\section{Technology}

During the winter, the system called Freshmaker enlarges the freshwater lens by pumping freshwater from a nearby water ditch into a 70-meter-long shallow horizontal well. The underlying freshwater groundwater is continually intercepted and discharged into another ditch by a second, deeper horizontal well. In the summer, when irrigation water is scarce, the extended freshwater lens may be used for irrigation.

\section{Future Scope}

Recharging groundwater systems with high quality treated wastewater or recycled surface water can be used for future preparation and maintenance of saltwater intrusion in coastal aquifers. According to the current review, implementing these cost-effective water supplies would help reduce the risks of both saltwater intrusion and flooding at the same time. To track inland saltwater advancement, coastal areas need modern monitoring systems that include observation wells with multiple screens at various depths, as well as sensors and automated database storage systems. The implementation of a comprehensive decision support system that encompasses a broad range of hydraulic components of surface-subsurface water interactions is another potential area for future saltwater intrusion management (e.g., evaporation, natural recharge, artificial recharge, and groundwater pumping). To simulate aquifer responses to various management scenarios, this decision method should be combined with numerical models. This integrated method can be used to determine the best management arrangements for each scenario. Before implementing each saltwater intrusion control measure, the effects of parameter uncertainty on model calibration and the optimal results of each saltwater intrusion control measure should be investigated.

\section{Conclusion}

This paper presented a combined review on the common method "Management of coastal aquifers with special reference to sea water intrusion and its remediation". Coastal region is home to a huge portion of the world's population and economic activity. The subject is also generating a lot of concern around the world because of its rise in population in coastal areas of both permanent and temporary. A stable water source is essential for their future growth. Sea water contamination poses a risk of salinization. The primary motivator is aquifers, over exploitation, which induces land subsidence and thus add problems of salinization to its uncertainty. It also exhibits that in both East and West coast of India the sea water intrusion is more distinguished. Variety of subjects had also been covered like groundwater pollution, sea water intrusion form and its causes, modelling and case study. Sea water contamination causes a serious threat to freshwater supplies in marine aquifers. Groundwater salinization is one of the most significant contaminants in marine aquifers. Recharging into a percolation pond often improves the efficiency of the groundwater. Understanding the dynamics of seawater infiltration under various hydraulic pressures, as well as planning methods, groundwater simulation may be used as a method for sustainable groundwater management. 


\section{References}

1. P. Prusty, S.H. Farooq 2020, Seawater intrusion in the coastal aquifers of India - A review, HydroResearch 3 (2020) 61-74 2. Bear J, Cheng, AH, Sorek S, Quazar D, Herrera I (1999) Seawater intrusion in coastal aquifers,

concepts, methods and practices. Kluwer Academic, Dordrecht. ISBN 0-7923-5573-3

3. Ataie-Ashtiani, B., Volker, R.E., Lockington, D.A., 1999. Tidal effects on sea water intrusion in unconfined aquifers.

J. Hydrol. 216, 17-31.

4. Barazzuoli, P., Nocchi, M., Rigati, R., Salleolini, M., 2008. A conceptual and numerical model for groundwater management: a case study on a coastal aquifer in southern Tuscany, Italy. Hydrogeol. J. 16 (8), 1557-1576.

5. Carretero, S., Rapaglia, J., Bokuniewicz, H., Kruse, E., 2013. Impact of sea-level rise on saltwater intrusion length into the coastal aquifer, partido dela costa, Argentina. Cont. Shelf Res. 61-62, 62-70.

6. CGWB, 2014. Report on status of groundwater quality in coastal aquifers of India. CGWB, Faridabad, Haryana.

7. Abdalla, F., 2016. Ionic ratios as tracers to assess seawater intrusion and to identify salinity

sources in Jazan coastal aquifer, Saudi Arabia. Arab. J. Geosci. 9, 40. https://doi.org/

10.1007/s12517-015-2065-3.

8. Adyalkar, P.G., Ghosh, P.C.,Mehta, B.C., 1981. On the salinity of groundwater in South 24-

Parganas District,West Bengal, India. Studies in Environmental Science. Elsevier B.V.,

pp. 63-67 https://doi.org/10.1016/S0166-1116(08)71883-1.

9. Ismail Abd-Elaty, Hany F. Abd-Elhamid, and Abdelazim M. Negm 2017, Investigation of Saltwater Intrusion

in Coastal Aquifers, DOI 10.1007/698_2017_190, C Springer International Publishing AG 2018 